\title{
PSICANÁLISE: UMA LEITURA HEIDEGGERIANA
}

Zeljko Loparic*

SÍNTESE - O texto não fala de um confronto entre Heidegger e Freud. A crítica da psicanálise propõe uma nova leitura na forma de uma desconstrução conceitual. $\mathrm{O}$ autor faz uma análise da origem metafisica dos conceitos de psicanálise e de seu instrumental mitológico, sugerindo um universo conceitual que nasce da superação da metafisica. Trata-se de "substituir modo de teorizar da psicanálise por um modo de pensar $e$ de conhecer radicalmente diferente."

PALAVRAS-CHAVE - Freud, Heidegger, psicanálise, reconstrução.
ABSTRACT - The subject of the text does not oppose Heidegger and Freud. The psychoanalysis criticsm proposes a new interpretation as a conceptual desconstruction. The author analyses the metaphysical origin of psychoanalytical concepts. In this way he focuses the relations between the mythological thinking and the conceptual ground that comes fron the overcoming of metaphysics. The author propose "the substituition of the psychoanalytical current ways of theorising by a radical new way of thinking and knowing".

KEY WORDS - Freud, Heidegger, psychoanalysis, desconstruction.

\section{1 - Heidegger, leitor de Freud}

Sabemos que Heidegger leu Freud. Não por curiosidade intelectual própria, pois tinha "uma aversão abismal a toda psicologia científica moderna". ${ }^{1}$ Nem mesmo por ter tido problemas psiquiátricos: quando, na primavera de 1946, proibido de lecionar, passando por dificuldades materiais sérias, Heidegger sofreu um colapso físico e psiquico e foi obrigado a procurar um tratamento, ele não escolheu como terapeuta um analista freudiano. ${ }^{2}$ A sua preferência caiu sobre Viktor E. v. Gebsattel, que pertencia à linha da psiquiatria conhecida como medicina ou psicologia antropológica, inaugurada por Ludwig Binswanger, parcialmente inspirada

* Professor da Universidade Estadual de Campinas (UNICAMP) e da Pontificia Universidade Católica de São Paulo (PUCSP).

1 Cf. Boss, 1977 , p. 34 .

2 De resto, mesmo se preferisse um analista freudiano, Heidegger teria tido dificuldade em achar um. A recepção alemã da psicanálise freudiana foi e continua sendo bastante lenta e reticente. Pensadores de peso, entre eles Karl Jaspers, emitiram pareceres muito negativos sobre Freud. Sobre esse ponto, cf. Decker 1977.

\begin{tabular}{|l|l|l|l|l|l|}
\hline VERITAS & Porto Alegre & v. 43 & $\mathrm{n}^{0} 1$ & Março 1998 & p. 25-41 \\
\hline
\end{tabular}


na análise existencial do próprio Heidegger e fortemente crítica do fisicalismo da psicanálise freudiana. ${ }^{3}$

Quem moveu Heidegger a debruçar-se, pela primeira vez na vida, no final dos anos 50, sobre os textos freudianos foi Medard Boss, seu amigo pessoal que, décadas antes, foi a Viena para ser analisado por Freud. Boss conta que ao ler os trabalhos teóricos, isto é, metapsicológicos de Freud, Heidegger não parava de balançar a cabeça: "Heidegger não queria de modo algum acreditar que um homem de uma perspicácia tão grande como Freud pudesse elocubrar construções meramente fictícias e tão artificiais, tão alheias ao ser humano, e até mesmo absurdas. Ele sentia-se literalmente mal fazendo essas leituras." Os Escritos sobre a técnica, nos quais Freud dá conselhos sobre a conduta prática das análises terapêuticas dos pacientes neuróticos tornavam-no mais conciliador. Por que essa diferença de atitude? Boss tenta explicar: "Heidegger logo descobriu a flagrante contradição entre esses e aqueles textos; a saber, o abismo intransponível entre o determinismo científico absoluto da sua teoria e a repetida ênfase sobre a libertação do paciente por meio da prática psicanalítica". 5

Em 1974, Boss publicou uma segunda e ampliada edição de um longo tratado sobre medicina e psicologia em que desenvolve, de maneira sistemática e histórica, essa contradição que opõe determinismo teórico à prática clínica libertária de Freud. Depois de destacar a incompatibilidade entre o conceito fisicalista da energia libidinal e o de intencionalidade - de captação de algo como algo - Boss retoma a linha principal da objeção heideggeriana contra as especulações metapsicológicas em geral: 'Em nenhuma teoria determinista algo como 'sentido' ou mesmo representação de 'liberdade' tem qualquer lugar possível" ${ }^{6}$ Mesmo nas análises dirigidas por psicanalistas ortodoxos, prossegue Boss, ocorrem muito mais coisas do que pode ser explicado por meio de conceitos da teoria da libido e esse

3 Sobre o tratamento de Heidegger com v. Gebsattel, cf. Ott, 1988, p. 322-323. Segundo Ott, essa estada de Heidegger no sanatório de v. Gebsattel forneceu ou, melhor, fortaleceu o embasamento da sua futura estreita colaboração intelectual com a linha "daseinsanalítico-antropológica" de psiquiatria à qual pertencia v. Gebsattel e que foi inaugurada por Ludwig Binswanger e Medard Boss. Essa afirmação contém um duplo engano. Em primeiro lugar, embora a antropologia psiquiátrica de Binswanger seja em parte baseada em Ser e tempo, Heidegger nunca se entusiasmou com essa recepçāo da sua obra. Pelo contrário, ele sempre distinguiu a sua interpretação daseinsanalítica do ser humano de qualquer antropologia. Esta última se reduz, de acordo com Heidegger, a uma posição que no fundo já sabe o que é o homem e que, por isso, não pode perguntar quem ele é. Se colocasse essa pergunta "a antropologia deveria reconhecer-se abalada e ultrapassada" (cf. Heidegger, 1938, p. 103). Em segundo lugar, Medard Boss, desde que entrou em contato com Heidegger, distanciou-se enfaticamente da medicina e psicologia antropológicas e, portanto, não pertenceu à mesma linha teórica que Binswanger e v. Gebsattel (cf. Boss, 1974, p. 216-217). Pelo que me consta, Heidegger nunca "colaborou" com Binswanger, enquanto aceitou Boss como interlocutor.

Cf. Boss, 1977, p. 34-35.

5 Além de colocar Freud nas mảos de Heidegger, Boss teve ainda o mérito de convencê-lo a vir a sua casa em Zollikon, perto de Zürich para debater os problemas da psicopatologia e medicina. Esses seminários, que ocorriam a cada semestre, em várias sessões de até 14 dias, durante 17 anos, a partir de 1958, estão publicados em Boss (org.) 1989. Esse material não é tratado aqui, pois será objeto de análise de um artigo meu em preparação. Boss, 1974, p. 560. 
mais só pode ser captado pela analítica existencial de Heidegger, em particular, em termos dos seus conceitos de "estar-com-outros" e de "preocupação precursora"?

\section{2 - Caracterização da leitura heideggeriana da psicanálise}

Por ter recebido influência direta de Heidegger, a obra de Boss constitui-se numa referência capital para qualquer tentativa de elaborar uma leitura de Freud do tipo heideggeriano. Boss explicitou muito bem a principal objeção que Heidegger faz aos escritos metapsicológicos de Freud: o determinismo, de origem metafísica. Boss também determinou com precisão a natureza geral de uma leitura heideggeriana da psicanálise: esta deve ser feita no mesmo estilo que a desconstrução da metafísica. Isso significa que a metapsicologia deve ser entenđida, ela mesma, como um exemplo do uso da metafísica a ser desconstruída.

Poder-se-ia objetar que, por serem dirigidos essencialmente aos textos da metafísica, as análises desconstrutivas de Heidegger não podem ser estendidas aos textos científicos como os de Freud. Essa objeção não procede. A principal razão é que, para Heidegger, a metafísica ocidental não está tão somente nos livros de metafísica. Nesses livros, ela apenas chega a sua manifestação plena. A metafísica não trata de algo abstrato, pelo contrário, ela trata de algo mais concreto do que qualquer questão cotidiana concreta. ${ }^{8}$ Por explicitar o acontecer fundante da história do Ocidente, a metafísica diz respeito também ao que subjaz a todas as manifestações da vida do Ocidente, permeando inclusive a produção científica. Ler Freud heideggerianamente significa, portanto, identificar e desconstruir a metafísica embutida na sua obra.

Embora tenha dado contribuiçōes importantes à leitura heideggeriana da psicanálise, Boss não a desenvolveu em toda a sua amplitude e nem esgotou todas as suas possibilidades. Suas análises apresentam duas insuficiências principais. Em primeiro lugar, Boss não distingue, com clareza necessária, entre as duas fases do pensamento heideggeriano: entre o Heidegger I, de Ser e tempo (1927), criador da analítica existencial e da ontologia fundamental, ambas baseadas numa hermenêutica do estar-aí humano, e o Heidegger II, posterior a 1936, pensador da história da metafísica ocidental e da época da técnica, expositor da linguagem de poetas e intérprete dos pré-socráticos, que faz a vigilia do outro começo (desta vez não grego) do pensamento do ser (presença constante). Em outras palavras, Boss não discrimina, com a ênfase cabivel, entre dois quadros de leitura heideggeriana da tradição ocidental em geral.

7 Traduzo por "preocupaçäo precursora" a expressão heideggeriana "vorspringende Fürsorge", introduzido no parágrafo 26 do Ser e tempo em oposição à "preocupação substituidora", "einspringende Fürsorge". Segundo Boss (1977, p. 7), Heidegger, ele mesmo, teria apontado o conceito de preocupação precursora como a referência-chave para qualquer teoria fenomenalmente satisfatória da terapia das doenças psíquicas.

8 Heidegger concorda, por exemplo, com Marx, que o mundo não precisa mais ser interpretado, que ele deva ser mudado. Mas, acrescenta Heidegger, essa exigência de Marx, por seu turno, pressupõe uma mudança no modo de pensar de Marx, mudança que Marx ele mesmo não tematizou de modo suficiente. Cf. Heidegger, 1963, p. 236. 
Por essa razão, e essa é a segunda insuficiência dos seus textos, Boss não deu atenção suficiente às diferenças entre $o$ conceito de desconstrução da primeira $e$ da segunda fase. Com a reviravolta que separa o Heidegger I do II, o próprio programa heideggeriano de desconstrução da metafísica e, por conseguinte, da ciência ocidental (já que, conforme Heidegger, a ciência ocidental sempre foi e continua sendo constituída sobre fundamentos metafísicos) sofreu modificações não negligenciáveis que precisam ser devidamente temarizadas.

Na primeira fase, a tarefa de destruição da metafísica e da ciência consiste em situar esses modos de teorização no interior do tempo do acontecer do estar-aí humano. Trata-se de mostrar como os conceitos básicos da metafísica (idéias platônicas, a substância aristotélica, a subjetividade cartesiana, etc.) ou da ciência (as leis de Newton, o aparelho psíquico de Freud, etc.) podem ser derivados dos modos mais originários do ser do estar-ai, isto é, constituídos a partir da compreensão pré-teórica, ante-objetiva, do sentido da presença das coisas.

Uma vez remetidos à origem, esses modos de pensar recebem, como diz Heidegger, a sua "certidão de nascimento" eles ficam autenticados, isto é, expostos enquanto possibilidades autênticas do estar-aí no mundo. É nesse sentido que Heidegger fala, ainda, de um "conceito existencial de ciência". Essa autenticação tem o seu preço: os modos de pensar metafísicos e científicos perdem a sua originalidade e exclusividade e, com isso, a sua força sobre o existir humano. É nesse sentido que eles são "destruídos" e negativados. ${ }^{9}$

Na segunda fase, a desconstrução tem a tarefa de mostrar que a metafísica deriva não dos modos originários de ser do estar-aí humano e sim dos "destinamentos" que marcam a "acontecência" do ser. Nesse contexto, desconstruir significa reconhecer, nos conceitos metafísicos dominantes em diferentes épocas, um chamamento ao homem proveniente do ser ele mesmo. O mais recente chamamento do ser - que, de acordo com Heidegger, seria também o terminal - é o que determina a presença do ente como tal no seu todo em termos da técnica. Aqui, a técnica é pensada como instalação calculadora de todas as coisas, como armação que monta e desmonta tudo o que há, a ponto de ameaçar desfazer até mesmo a essência do homem como o destinatário dos destinamentos do ser, determinandoo como mero produto numa cadeia infinita de produtos.

Terminada a tarefa de redução das idéias da metafísica à acontecência do ser, coloca-se uma nova tarefa que não tem equivalente em Heidegger I. Não se busca mais tão somente a origem ontológica do modo de ser do homem em que se fundamenta a metafísica e a ciência, mas o ultrapassamento (Überwindung) definitivo de tais formas de ser. Não se trata mais de definir um conceito ontologicamente verdadeiro da metafísica ou da ciência a partir do compreender pré-metafísico e pré-cientifico. A tarefa, agora, é a de substituir o modo de pensar metafísico e científico em geral por um modo de pensar novo, não metafísico nem científico, e, nesse sentido, ultrapassar a teorização metafísica e científica enquanto tal. Tendo descoberto a periculosidade da técnica e, com isso, da metafísica no seu todo, a desconstrução heideggeriana perde todo o seu caráter conservador.

9 Cf. Ser e tempo, parágrafo 69.b. A questão de saber se Heidegger I è ainda um pensador fundacionista é discutida em Loparic, 1996c. 
O que vale para a desconstrução da metafisica e a ciência em geral, vale também para a desconstrução da psicanálise. No contexto de Ser e tempo, a desconstrução da psicanálise no estilo da primeira fase exige, em particular, a derivação positiva dos modos de ser e de pensar do homem com as quais trabalham os terapeutas freudianos. A fim de tornar esse ponto mais preciso, consideremos os esboços de derivação de alguns conceitos psicológicos e psicanalíticos feitos por Heidegger em Ser e tempo.

No parágrafo 41 de Ser e tempo, Heidegger afirma que o fenômeno central do estar-ai, o cuidado (Sorge), possui uma unidade indecomponível, razão pela qual não pode ser construído a partir de atos particulares ou impulsos (Triebe). ${ }^{10}$ Pelo contrário, são os impulsos, as vontades e os desejos, os pendores e os ímpetos, que devem ser interpretados a partir do fenômeno fundamental e unitário de cuidado. Nesse mesmo parágrafo, bem como no parágrafo 43.b, Heidegger indica como essa interpretação pode ser iniciada. Todo impulso e ato de querer está "mundo afora" a fim de algo que já foi descoberto a título de coisa que nos resiste e impede o nosso "querer de passar adiante". O querer que se choca com uma tal resistência é, na origem, um estar-aí num "todo de deixas" a que se submete a nossa ocupação diária com as coisas.

É fácil perceber que essas observações de Heidegger oferecem um ponto de partida para uma reinterpretação da teoria freudiana numa chave não fisicalista, que não é nem mesmo psicológica e sim propriamente daseinsanalítica. Não se trata simplesmente de negar que o estar-aí humano tenha a estrutura de um aparelho mecânico movido a "pulsões". A leitura desconstrutiva da psicanálise no estilo do Heidegger I não consiste no simples afastamento do corpo das doutrinas psicanalíticas de concepções da metafísica (tais como o princípio de causalidade) e da ciência fisicalista (tais como o aparelho psiquico). Ela tampouco se reduz ao emprego direto dos conceitos da analítica existencial de Heidegger. Esses conceitos não foram elaborados para descrever a estrutura geral do estar-aí e não para tratar de assuntos específicos do interesse da psicanálise. A tarefa da desconstrução é mais complicada e tem dois componentes positivos ou reconstrutivos: a) tornar claro por meio de que modificações do seu sentido do ser o estar-aí passou a existir, a determinar-se e a ser determinado como uma mera coisa intramundana, por exemplo, como uma máquina ou aparelho que desempenha funções de acordo com os impulsos de certas forças fundamentais; b) oferecer uma fenomenologia dos impulsos por meio da sua cerivação do cuidado que poderia servir de fundamento para uma ciência psicológica constituída de acordo com o conceito existencial de ciência. A desconstrução implica, portanto, na "reconstrução", isto é, na elaboração de uma fenomenologia da acontecência do estar-ai (desde a gravidez, a relação mãe-bebê e a infância até a constituição da vida adulta), da saúde, da doença, da relação terspêutica e da cura, fenomenologia que até o presente momento não foi elaborada por ninguém. ${ }^{11}$

10 Heidegger usa aqui o termo Trieb num sentido muito mais amplo que o de Freud.

11 Nem mesmo Boss empreendeu tal tarefa. Em vez de trabalhar, no estilo de Heidegger, o material clínico, ele se limitou, em geral, em aplicar a esse material os conceitos já prontos das análises estruturais heideggerianas. Com isso, Boss não fez muito mais do que dar alguns primeiros passos 
A desconstrução característica da segunda fase, se aplicada à psicanálise, pede outra coisa. Ela pede que sejam identificados os destinamentos do ser, depositados nos grandes livros da metafísica ocidental, que fizeram com que o existir humano, essencialmente questionável, de que tratam os psicanalistas, tenha passado a vigorar como um existir dessa ou daquela maneira positiva e objetiva, por exemplo, como um processo mecânico. Essa tarefa redutiva se completa por uma adicional, a que visa substituir, no estudo do homem, os modos de teorizar característicos da psicanálise por um modo de pensar e de conhecer radicalmente diferente.

De novo, o material disponível que possa ilustrar essas afirmações é bastante escasso, já que Heidegger mesmo nessa segunda fase dedicou pouca atenção à psicanálise. Um texto, no entanto, merece ser lembrado. Nas lições de 1951/52, intituladas $O$ que (se) chama pensar?, Heidegger aproxima a psicanálise da "logistica". Herança cartesiana e leibniziana, a logística, teoria do cálculo formal, vale, hoje em dia, "como a única forma possível da filosofia rigorosa, porque seus resultados e seus procedimentos são de utilidade imediata e segura para a construção do mundo técnico. É por isso que hoje, na América e em outros lugares, a logística começa a conquistar o domínio sobre o espírito a título de autêntica filosofia do futuro." Depois de ter determinado o modo essencial como se dá o pensamento na época da técnica - a saber, como a mathesis universalis, que resolve todos os problemas calculando, - Heidegger explicita a situação da psicanálise: "Com o acoplamento sui generis da logística com a psicologia moderna e a psicanálise, bem como a sociologia, fica perfeito o conglomerado de empresas /Konzern/ que constituem a filosofia que se aproxima." Palavras incisivas que colocam a psicanálise no rol de empreendimentos intelectuais que visam a determinação interminável e não a libertação final do homem. Heidegger continua: "Entretanto, esse assédio não é de modo algum uma maquinação do homem. Antes, essas disciplinas são levadas pelo destinamento de um poder que vem de longe e para o qual talvez as palavras gregas poíesis (poesia) e téchne (técnica) permaneçam nomes adequados, à condição de que nós, seres que pensamos, estejamos nomeando aquilo que dá a pensar."12

Texto de importância capital que ilustra bem, apesar da sua concisão, o caráter "epocal" que Heidegger II atribui à psicanálise: ela faz parte do mesmo conglomerado de teorias que, na época da técnica, servem para exercer o controle técnico sobre o existir humano e, nessa medida, ameaçar a própria essência do homem. É sobretudo por isso que a psicanálise, na sua formulação tradicional, deve ser ultrapassada.

no caminho de uma fenomenologia dos distúrbios do estar-aí humano que, no essencial, ainda resta para ser feita. Seria um erro pensar que Lacan teria feito contribuições relevantes que vão na mesma direção. As suas ficçōes lingüisticas sobre a origem do desejo e sobre a cura são tão metafisicas e tão alheias à "fenomenologia fundamental" do estar-ai quanto as ficções fisicalistas (fisiológicas) de Freud.

Heidegger 1961, p. 10. No presente texto, Heidegger aproxima a poíesis da téchne, em desacordo com a posição que tomou em $A$ origem da obra de arte, de 1935. 
Num trecho do artigo Ciência e pensamento meditativo, de 1953, que tematiza a psiquiatria mas que pode, sem dúvida, ser aplicado à psicanálise, Heidegger tenta anunciar a alternativa ao modo de pensar da técnica. Ele escreve: "A psiquiatria trata da vida psíquica humana nas suas manifestações patológicas e isso significa sempre também nas suas manifestações sadiaș. Ela representa essas manifestações contra o pano de fundo da objetividade da unidade corpo-menteespirito. Na objetividade da psiquiatria mostra-se sempre o já presente estar-ai do homem. 0 estar-aí, em que o homem enquanto homem ex-siste, permanece o incontornável da psiquiatria." 13 O estar-aí de que fala Heidegger é algo que sempre necessariamente precede a teorização psiquiátrica, mas que a psiquiatria, enquanto pensamento objetivante do tipo cartesiano, não pode tematizar, nem mesmo "pressupor" no sentido preciso da palavra. Esse incontornável não é um a priori teórico da psiquiatria justamente por não ser algo objetivável, acessável a título de um objeto de representação. Trata-se de um prévio cujo sentido revela-se indizível para o pensamento teórico da tradição metafisica e científica.

Heidegger explica. Para os gregos, theorein significa ver o que se mostra nas e das coisas, ver os seus aspectos. A vida teórica que se abre ao puro reluzir das formas das coisas presentes e produz teorias, é colocada acima da vida prática, que se dedica ao agir e ao produzir. Os romanos traduziram o theorein por contemplari, e theoria por contemplatio, palavras que derivam de templum, lugar recortado e cercado. A vida "contemplativa" deixou de ser contraposta à prática e passou a ser pensada a partir de tractare, tratamento, elaboração, perseguição, securitização do que é real no sentido de efetivo e, por isso, tratável. Na modernidade cartesiana, o tratável tornou-se objetivável na representação e verbalizável em termos da linguagem da ciência. Essa determinação do modo da presença dominante das coisas prevalece ainda nos nossos dias, depois de ter sido explicitada, por Nietzsche, como vontade de poder.

A luz dessas observações sobre a modo de proceder que caracteriza a tradição intelectual dominante do Ocidente, o incontornável da psiquiatria (e da psicanálise), nomeado por de Heidegger, não é nem teorizável, nem contemplável, nem tratável, nem objetivável e, por isso, não é dizível na linguagem da ciência. É um modo de ser do homem que só pode ser aproximado por um pensamento que se libertou desse progressivo esquecimento do reluzir originário das coisas ainda considerado pelo gregos; esquecimento que constitui, segundo Heidegger, o acontecer fundamental da história do Ocidente. Um pensamento capaz de se abrir ao incontornável deve cessar de objetivar o existir humano. Ele deve se entregar à sua questionabilidade essencial, reconhecer a radical impossibilidade de teorizar e de dizer tudo sobre o homem. Tal pensamento não objetivante, que trabalha com a palavra quebrada, não permanecerá às escuras e sem rumo: ele receberá a sua direção ao con-siderar a presença das coisas dadas à luz do dia. ${ }^{14}$

13 Cf. Heidegger, 1954, p. 63.

14 Escrevo "con-siderar" para chamar a atenção para o significado etimológico dessa palavra "ver à luz da estrela (do dia), "ver à luz do Sol". - Sobre o uso da expressão "palavra quebrada" em Heidegger, cf. Loparic, 1995b, cap. 9. 
Heidegger adverte repetidas vezes contra o erro de identificar o pensamento que ele chama de meditativo (Besinnung) com a mística. A mística postula um modo de existir e um modo de conhecer alheios e superiores à existência e ao conhecimento normais. Nada disso é postulado por Heidegger. Quando fala em pensamento meditativo ou, como poderiamos também dizer, "con-siderativo", Heidegger não apela a nada fora do normal. Afirma apenas que o pensamento ocidental tomou o rumo teorizante, que esse rumo não é o único possível, que ele obscurece a manifestação originária do existir humano e, por isso, torna-se fonte de um perigo extremo para o homem (o perigo da dominação técnica) e, por fim, que podemos esperar convalescer desse rumo e iniciar um acesso a nós mesmos e às coisas ao mesmo tempo mais antigo e mais novo. ${ }^{15}$

Tampouco se pode falar, a propósito de Heidegger II, em mitologia. A mitologia, ao contrário da mística, objetiva visualizar o que não é invisível ou o que é apenas insuficientemente visível por imagens claras e familiares, geradas pela imaginação. $\mathrm{O}$ pensamento meditativo de Heidegger, por outro lado, não tenta representar o não representável. Em vez de visualizar o invisível, reconhece-o como tal e se retrai nos seus limites. Em vez de fantasiar, isto é, iluminar por meio de construções subjetivas o que só se vê de maneira deficiente, o con-siderar heideggeriano se satisfaz com o que enxerga à luz natural.

Não há como negar o caráter muito especial do estilo da leitura heideggeriana da psiquiatria e da psicanálise. Precisamos explicitá-la melhor. Para tanto, daremos, no que segue, um exemplo de desconstrução de um conceito de metapsicologia freudiana, o de aparelho psiquico, no estilo de Heidegger II.

\section{3 - O status da metapsicologia: mitologia, metafísica ou ciência?}

A tarefa de desconstrução da metapsicologia a título de metafísica deve defrontar-se, desde 0 inicio, com um complicador: 0 fato de a psicanálise ser permeada de formas de pensamento pré-metafísicas, isto é, mitológicas. A nossa doutrina das pulsões é, por assim dizer, a nossa mitologia, escreveu Freud já no fim da vida. E explicou: "As pulsões são entidades míticas, magnificas na sua indeterminação." Do mesmo cunho é a observação de Freud de que a sua metapsicologia é uma "bruxa". Essa metáfora sobre a metapsicologia, inspirada em Goethe, é usada por Freud para explicitar o caráter metafórico da metapsicologia ela mesma: "Sem a especulação e a teorização - eu quase disse: fantasia - não podemos avançar nesse campo."16 A palavra chave aqui é justamente a "quase dita", a "fantasia", pois é ela que designa mais precisamente o caráter dos conceitos metapsicológicos: eles são imagens construidas pela fantasia, imagens que não são nem podem ser controladas pela experiência ou razão teórica. Apesar de insatisfatórias, se consideradas no contexto de justificação, as imagens míticas favorecem o avanço da pesquisa. De que maneira? Elas permitem visualizar como e por quais meios acontecem certos processos psíquicos seja total seja parcialmente inacessiveis à observação direta. Ainda que arbitrária, essa visualização do

15 Em Loparic, 1990, cap. 8, fiz um estudo detalhado do conceito e dos tipos de perigo extremo.

16 Cf. Freud, Análise terminável e interminável, cap. 3. 
invisível e do insuficientemente visível facilita a organização teórica do material clínico, favorece a aplicação das técniças terapêuticas e afasta, pelo menos em parte, a objeção de que a psicanálise, quando fala, por exemplo, em pulsão de morte, estaria caindo em puro misticismo. ${ }^{17}$

É bem verdade que Freud fez esforços paralelos de aproximar as pulsões aos conceitos da metafísica ocidental, em particular, à vontade de vida e a negação da vontade de vida de Schopenhauer. Em Além do princípio do prazer, Freud não esconde que o barco da sua teoria das pulsões está atracado no porto da filosofia de Schopenhauer. Em Schopenhauer, de fato, a morte é "o verdadeiro resultado" e, nessa medida, a meta da vida, enquanto a pulsão sexual é a encarnação principal da vontade da vida. O mesmo tema volta em 1933, na segunda série de lições introdutórias. Na lição 32, Freud coloca-se a objeção de saber se a sua teoria das pulsões seria científica ou apenas uma versão da filosofia de Schopenhauer. Em vez de contestar essa objeção, Freud escreve: "Mas por que, minhas Senhoras e Senhores, um pensador ousado não poderia ter adivinhado o que, em seguida, foi confirmado por uma pesquisa detalhada, sóbria e penosa?"18

Existem, portanto, elementos de metafísica na metapsicologia de Freud. Estes não se reduzem à afinidade com a teoria da vontade de Schopenhauer. Toda a teoria freudiana das neuroses e da técnica terapêutica é devedora do paradigma que domina a metafísica moderna, o cartesianismo. São diretamente cartesianos ou, então, pós-cartesianos todos os conceitos básicos de Freud, como os de monismo ontológico (o homem faz parte da natureza), de sujeito de representação e de afeto, de aparelho psíquico, de princípio de prazer, de temporalidade linear, de principio de causalidade, de realidade interna e externa, o conceito de pulsão, finalmente, de representabilidade, de racionalizabilidade e de "dizibilidade" de tudo, inclusive da vida humana. O método de proceder na psicologia, por meio de metáforas dinâmicas, também já foi ensaiado, desde Leibniz, por filósofos modernos. No essencial, o lugar teórico de toda a teoria freudiana do inconsciente, inclusive da sexualidade, é o subjetivismo metafísico moderno.

A metafísica aparece explicitamente, ainda, na obra de muitos pós-freudianos, por exemplo, na de M. Klein. O seu conceito de ego (como centro que nasce com a capacidade de executar determinadas operações ou, ainda, de fazer funcionar certos "mecanismos"), o de mundo externo, (como consistindo, desde o início da vida do ser humano, de objetos de percepção), o de mundo interno (como o de objetos introjetados), o da guerra entre os objetos bons e maus (externos ou internos), o princípio de prazer fazendo as vezes do princípio de causalidade (pois a frustração é um dos motores básicos da máquina psiquica kleiniana), por fim, os instintos de morte e de vida que são verdadeiros agentes causais, tudo isso é uma maquinaria herdada do subjetivismo da filosofia moderna que invadiu a cultura ocidental e, como vemos no caso de Klein, até mesmo a percepção do cotidiano.

17 Cf. Freud, Além do principio de prazer, cap. 6.

18 O paralelo entre Freud e Schopenhauer não pára por aí. O conceito do inconsciente dinâmíco e do recalque também aparece já em Schopenhauer. Vale a pena verificar ainda o que Schopenhauer tem a dizer sobre a importância do instinto sexual e do seu primado em relação ao instinto de autoconservação. Sobre a história da descoberta do inconsciente, cf. Ellenberger, 1970. 
Além de recorrer à mitologia e à metafísica, Freud também buscou, bem entendido, modelos científicos, mais precisamente, biológicos, para as suas pulsões primitivas. Para muitos leitores, esse era o verdadeiro Freud, praticante da ciência natural, solidário tanto do projeto de desmitologização, empreendido já pela metafísica grega, como do esforço mais moderno de eliminação da própria metafísica do discurso da ciência. Essa leitura choca-se, contudo, não apenas com o espírito, mas também com a letra de Freud. Freud deixou bem claro que os seus modelos científicos das pulsões não passavam de metáforas, úteis sem dúvida para a organização do material clínico, mas essencialmente arbitrárias e, como tal, não susceptíveis de justificação seja empírica seja racional ou seja, que eram mitos científicos, parecidos com os que foram propostos, desde a Antigüidade, por um número de poetas-filósofos. ${ }^{19}$

Freud foi mais longe ainda. Em 1933, na carta a Einstein, ele reconheceu que todas as metáforas básicas comumente usadas pela ciência da natureza possuem o caráter mítico. Depois de admitir que a sua teoria de pulsões eróticas e destrutivas pode parecer uma espécie de mitologia, Freud pergunta a Einstein: "Entretanto, será que toda a ciência da natureza não termina numa mitologia do mesmo tiño? Será que hoje na física não acontece a mesma coisa?" O que Freud está sugerindo é que mesmo na mais desenvolvida das ciências modernas o processo de desmitologização, iniciado pela metafísica e pela ciência grega, ainda não acabou, pior, que mesmo na física a mitologia está presente com toda a força.

Nessa situação, a leitura da psicanálise do tipo heideggeriano que visa a desconstrução da sua metafísica, tem que se desincumbir de uma tarefa prévia, a de sua desmitologização. A distinção entre essas duas tarefas está clara em princípio: a desmitologização pretende afastar as imagens (fantasias) arbitrárias das entidades ou processos invisiveis ou dificilmente visualizáveis e substitui-las pelos conceitos fundamentados seja na experiência sensorial, seja na razão; a desconstrução da metafísica visa desmontar os conceitos abstratos, vazios, construídos pela razão para cobrir o invisível ou só deficientemente visível, e substituí-los seja pelas palavras referentes a modos do ser-presença das coisas dados à luz da analítica existencial (Heidegger I) ou como destinamentos do ser (Heidegger II) - seja pelo silêncio.

No contexto da psicanálise ortodoxa, entretanto, essas tarefas se confundem devido ao fato de que, muito freqüentemente, as mesmas entidades são explicitadas ora por imagens, isto é, na chave mitológica, ora por conceitos especulativos, isto é, na chave metafísica. Todas as principais entidades metapsicológicas - 0 aparelho psiquico, as forças, a energia, as pulsões, o dualismo das pulsões primitivas (Eros, Thanatos) - possuem esse caráter misto mitológico-metafísico. O mes-

19 O uso do mito contra a acusação de misticismo, fica evidente no recurso ao mito do andrógeno de Platão (cf. Além do principio do prazer, cap. 6). Por não poder explicar por nenhuma hipótese seja empírica, seja abstrata, a necessidade observada nos organismos vivos de reprodução de um estado anterior, Freud recorre à fábula platônica para ao menos tentar visualizar o surgimento de uma tal necessidade. Pela mesmo motivo, Freud recorre a Empédocles de Agrigento. O mito de conflito entre os principios cósmicos de amor (filia) e de luta (neikos) do grande poeta-filósofo grego, representa, diz Freud em Análise terminável e interminável, o exato equivalente e uma "confirmação" da sua própria doutrina do dualismo de pulsōes fundamentais (Eros e Thanatos). 
mo vale para os princípios - além do já mencionado princípio de causalidade, cabe lembrar a explicabilidade racional do comportamento dessas entidades. Eles são tematizados ora na forma de histórias, que comumente remetem aos mitos gregos, ora na forma de teses abstratas, ao gosto dos filósofos metafisicos. ${ }^{20}$

No que segue, tentarei exemplificar essa tese considerando o conceito freudiano de aparelho psiquico. Antes disso, gostaria de recordar brevemente alguns outros estilos de leitura, não heideggerianos, que são comumente praticados em relação à psicanálise. Esperamos, desta maneira, conseguir um contraste que nos permita focalizar melhor o que há de específico na leitura desconstrutiva.

O modo mais comum de ler a psicanálise é o científico, que acabamos de mencionar. Nesse estilo trabalham não apenas os expositores de Freud, (Fenichel, por exemplo), mas também os seus continuadores (Anna Freud) ou reformuladores (Hartmann, Laplanche). A pretensão à cientificidade da interpretação de Freud é mantida também por autores que ousaram introduzir modificações mais incisivas no corpo das doutrinas psicanalíticas, tais como M. Klein e Lacan. A grande parte das críticas epistemológicas da psicanálise, formulada por filósofos (Schafer, Grünbaum) é também dirigida ao seu suposto caráter cientifico. Mesmo os proponentes da propostas alternativas (Binswanger, v. Gebsattel, Minkowski), ainda navegam nas águas do discurso científico. $O$ que une todas essas leituras é o esforço de garantir a cientificidade da psicanálise freudiana, em oposição ao mito e à metafísica, esforço fadado ao insucesso devido ao caráter essencialmente híbrido mítico-metafísico-científico da doutrina da Freud.

Existem, bem entendido, leituras não heideggerianas que privilegiam 0 background cultural e, em particular, filosófico em que Freud trabalhou e que codeterminou a sua produção teórica. Aqui cabe mencionar, em particular, os bastante elucidativos trabalhos de Assoun. Eu mesmo, tentei, em alguns textos, uma leitura de Freud a partir da teoria kantiana da ciência natural. ${ }^{21}$ Recentemente, Jurandir F. Costa propôs, seguindo Rorty, uma leitura pragmática da psicanálise. Trata-se de uma abordagem mista. Por um lado, Jurandir quer-se intérprete da ciência freudiana. Por outro lado, ele lê Freud à luz de teses filosóficas desenvolvidas no interior do neopragmatismo e da filosofia analítica contemporâneos. ${ }^{22}$

Um dos poucos que encararam a psicanálise explicitamente como mitologia e que a submeteu, a esse título, a um exame crítico-filosófico foi Popper. O modo psicanalítico de tratar os fatos é idêntico ao utilizado por Homero para contar as estórias dos deuses do Olimpo. Nos dois casos, há uma descrição de certos fatos, só que à maneira de mitos, razão pela qual a psicanálise deve ser vista como uma doutrina pré-cientifica, assim como de resto toda a metafísica. ${ }^{23}$ Wittgenstein é um outro filósofo que explicitamente caracterizou Freud como um grande produtor de

20 Compare, por exemplo, as passagens de Freud sobre o "Deus Logos" com a sua profissão de fé na razão científica. Compare, por exemplo, as passagens de Freud sobre o "Deus Logos" com a sua profissão de fé na razảo científica.

Cf. Loparic, 1985; e Blum, 1996.

22 Para uma análise critica da leitura de Jurandir F. Costa, cf. Loparic, 1995a.

23 Cf. Popper, 1963 , p. 38 e nota. 
mitos. ${ }^{24}$ Nem Poper nem Wittgenstein devem, entretanto, ser aproximados de Heidegger: ambos desconhecem o problema heideggeriano do sentido do ser, bem como o do espaço (seja ontológico-existencial, do Heidegger I, seja ontológicodestinamental, do Heidegger II) de constituição desse sentido, problemas que presidem, como vimos, uma leitura especificamente heideggeriana da psicanálise.

\section{4 - Um exemplo de desconstrução}

Gostaria de ilustrar o procedimento de desconstrução de psicanálise no estilo heideggeriano, tomando como exemplo o conceito de aparelho psíquico de Freud. Devido ao fato de que esse conceito possui também caráter metafórico, isto é, mitológico, o mesmo material pode servir também como exemplo de desmitologização. ${ }^{25}$ Como estilo de leitura, utilizarei sobretudo o do Heidegger II, baseado em considerações sobre a acontecência do ser depositada nas obras dos grandes filósofos do Ocidente. ${ }^{26}$

A mente, ensina Freud, serve-se de um aparelho para executar suas atuações ou "performances". A mente dispöe ainda de energia, chamada libido, que faz andar o aparelho. Que pode fazer 0 aparelho psíquico freudiano? Em principio, gerar todas as formações psiquicas, tanto conscientes como inconscientes.

Um aparelho geral, supostamente capaz de imitar todas as funções observadas do psiquismo, foi elaborado por Freud pela primeira vez no Projeto (1895). Em textos subseqüentes, Freud descreve vários mecanismos ou aparelhos näo mais gerais, mas especificos para esse ou aquele tipo de performance. O mecanismo descrito em Interpretação dos sonhos, por exemplo, é proposto como produtor de sonhos. Para sonhar, ele faz várias operaçōes, entre elas a de inverter o fluxo da energia e de regredir, nos três sentidos dessa palavra: espacialmente, formalmente e temporalmente.

Os diferentes tipos de aparelho psíquico ou melhor, os diferentes mecanismos especíicos, têm, via de regra, modelos físicos. No Projeto, a imagem é emprestada da fisiologia, da hidrodinâmica e da eletrodinâmica. Trata-se de um aparelho composto de neurônios, mutuamente conectados, capazes de fazer circular e de armazenar energia de natureza não especificada. Em Interpretação dos sonhos, o psiquismo é comparado ao microscópio e ao aparelho fotográfico. Trata-se de um tipo de visor, capaz de produzir efeitos visuais. Entre os modelos físicos posteriores, os mais notáveis são o bloco mágico, um engenhoso artefato capaz de guardar memória, e o reservatório ou caldeirão de energia, que exerce funções dinâmicas.

Qual é a origem desse conceito freudiano de aparelho psíquico? No essencial, é o projeto de mecanização da imagem do mundo e do ser humano que se iniciou com a Antigüidade grega e que foi explicitado, em Nietzsche, como vontade de

24 Sobre a leitura wittgensteiniana de Freud, cf. Bouveresse, 1991.

25 Um estudo mais detalhado desse tema encontra-se Loparic, 1997.

26 Ao fazer essa escolha, deixo em aberto a questão de saber como é possível unificar os resultados dos dois tipos de leitura heideggeriana da psicanálise. O estudo dessa questão, isto é, da relação entre Heidegger I e Heidegger II excederia de longe os limites do presente trabalho. 
poder. $\mathrm{Na}$ Grécia, o conceito de máquina ainda é reduzido à geometria e a certos engenhos técnicos. Máquina, mekané, significa guindaste, engenho bélico, máquina de teatro (pela qual deuses descem das alturas) e, de modo geral, é um meio artificial de fazer alguma coisa. Contudo, a execução de ações não implicava, de maneira geral, maquinização. Mais ainda, as coisas em geral, os seres vivos inclusive, não eram máquinas. É verdade que, em Platão, a alma é concebida como um "autômato", mas apenas no sentido de poder mover-se a si mesma, sem precisar de estímulos externos. Esse movimento não é associado a nenhum mecanismo ou engenho.

É apenas na Idade Média que o maquinismo na mente (e na natureza) começou a ser introduzido, em função da mudança de pergunta fundamental sobre o homem. A questão da essência ou da natureza do homem tornou-se secundária em relação a uma pergunta nova que dizia respeito à potência do homem. Não se queria mais saber, como na Grécia antiga, que é e como existe o homem. Agora, a questão dominante passava a ser: o que o homem pode fazer? $\mathrm{O}$ primeiro a dar força a essa pergunta foi Raimundo Lúlio, um místico catalão do século XIII. Foi ele quem, para responder a ela, postulou no homem a existência de um ingenium mental, capaz de resolver todos os problemas de teologia e de filosofia por meio de uma combinatória de letras do alfabeto.

Descartes retomou as idéias de Lúlio, algebrizou a sua combinatóna e explicitou os conceitos de máquina corpórea e máquina mental. A primeira obedece às leis da geometria e da física. A segunda procede por algoritmos algébricos (regras de cálculo). Leibniz acrescentou à álgebra o cálculo diferencial. A matemática das séries infinitas passou a dar forma às leis dos autômatos contínuos. Assim surgiu, pela primeira vez, a idéia de um deus que cria e que mantém o mundo, calculando. O mesmo Leibniz transformou a enteléquia aristotélica em vis, força mecânica. Estava formado o conceito de autômato no sentido moderno: engenho automotor capaz de executar uma infinidade de tarefas (resolver uma infinidade de problemas) de um determinado tipo. ${ }^{27}$

Tributária do projeto de mecanização da imagem do mundo e do ser humano, a teoria freudiana do aparelho psíquico se situa e se desenvolve no interior da teoria cartesiana da subjetividade, definitória da modernidade ocidental. Na tradição dominante do subjetivismo cartesiano, a mente é uma substância que pode calcular porque pode representar. Não se trata de uma substância qualquer, mas de uma substância fundante, cujas operações medem tudo o que existe. No cartesianismo, o mundo se reduz à realidade objetiva dada na representação. ${ }^{28}$

Qual é o estatuto teórico da teoria freudiana do aparelho psíquico? Muitos dos que fazem uma leitura realista de Freud em geral, atribuem também a essa teoria a pretensão à verdade objetiva. Não há dúvida que Freud estava comprometido com a busca da verdade objetiva. Mas existem fortes evidências de que ele não concebia as suas versões do aparelho como verdades explicativas e sim como,

27 Um estudo detalhado da história do processo de mecanização da imagem do mundo foi feito em Dijksterhuis, 1961.

28 Sobre o subjetivismo cartesiano, cf. Loparic, 1996b. 
no máximo, construtos ou convenções heuristicas. A teoria freudiana tem, de fato, o estatuto de uma metáfora, de mito construído de acordo com o princípio de determinismo universal, que serve para apenas visualizar para deste modo, conectar e ordenar os dados clínicos. O aparelho é a casa das bruxas e, ainda assim, uma casa cuja planta nos é pouco conhecida: eis como poderíamos caracterizar 0 aparelho psíquico da psicanálise, por analogia ao que o próprio Freud diz sobre as pulsões.

É nesse contexto que se situa também a afirmação de Freud de que a sua teoria do aparelho é uma teoria do como-se, no sentido do kantiano Vaihinger: tratase a mente como se fosse uma máquina; não se afirma que ela é uma máquina mas que, pelo menos, em certos casos, age como se fosse uma. Não se pergunta o que é o sujeito, mas o que é que ele pode fazer. ${ }^{29}$

Como ultrapassar radicalmente a metafísica da mecanização do mundo, embutida na psicanálise? Para tanto, não basta desconstruir os conceitos relativos ao sujeito moderno como objeto de estudo e de tratamento. É preciso substituir a própria pergunta que, desde Lúlio, guia o maquinismo: o que o homem pode fazer? Haveria uma outra pergunta sobre o homem que poderia assumir o papel de guia? Talvez aquela que já aparece em Kant, num das suas lições sobre a lógica, e que parece ter uma força premonitória: o que é o homem?

Sabemos que Heidegger restituiu a essa questão a sua força original. Já na sua primeira fase, Heidegger faz ver que o homem não é nem a mente, nem o corpo, nem uma união qualquer de mente e corpo, nem mesmo um processo natural causal. O homem não é coisa alguma, ele apenas acontece. Em vez de pesquisar a estrutura da mente, cabe indagar sobre a estrutura da acontecência do existir humano, para descobrir que esta não é outra do que a estrutura do tempo desse acontecer. O homem não é uma máquina de produzir "performances", ele é o próprio tempo, o "tempo-ser" (Zeit-Sein). A capacidade de viver não se reduz ao que pode realizar um aparelho, mas ao que pode acontecer com e no estar-aí humano no mundo.

$\mathrm{Na}$ sua segunda fase, Heidegger verá o homem como algo diferente: como o endereçado dos destinamentos em que se manifesta, isto é, se torna verdadeiro, o ser no sentido da metafisica ocidental, isto é, como presença constante. O homem é o correspondente das remessas dos modos da presença, tal como determinados, ao longo da história da metafísica, desde Platão a Nietzsche. Por isso mesmo, o homem pode esperar que, no futuro, o ser lhe seja entregue não mais como mera presença constante e sim de maneira distinta. Heidegger ensaia dizer esse novo sentido do ser: doação a partir de um retraimento indizivel. A filosofia, que inventou a máquina e o sujeito, despede-se, assim, desses dois conceitos como pertencendo à fase terminal da metafísica ocidental, à época da técnica. Fase a ser superada ou, melhor, deixada de lado e abandonada a si mesma.

29 Analisei esse ponto em Loparic, 1985. 


\section{5 - Depois da desconstrução}

Como fica a psicanálise depois da desconstrução? Essa pergunta recebe uma urgência especial da necessidade de se evitar que a psicanálise se confunda com o modo de pensar meditativo de Heidegger ${ }^{30} \mathrm{~A}$ resposta a essa pergunta pode ser dada a partir da observação de que a psicanálise, se lida ao modo de Heidegger II, não deve nem pode cuidar da doação do ser como tal. Essa é a tarefa do novo pensamento fundante anunciado por Heidegger. A tarefa da psicanálise permanece a de cuidar da doença e da saúde psíquicas (psicossomático). A novidade trazida pela interpretação heideggeriana não está na modificação da tarefa concreta da psicanálise, mas na maneira como é concebido o ser humano: a saber, como existência essencialmente questionável, só acessivel ao pensamento meditativo, irredutível às imagens e aos conceitos do pensamento "teórico" e "objetivante"; existência indizível na linguagem da ciência, que não pode ser "tratada" à luz do principio de causalidade, mas apenas "con-siderada".

É possivel ainda chamar de psicanálise uma doutrina que eliminou do seu corpo os fundamentos do tipo mitológico e metafísico? É possível elaborar uma doutrina que ainda seja psicanálise e que não seja nem determinista, nem objetivante, nem postule a "dizibilidade" essencial do acontecer humano ? Creio que sim. A prova disso é a psicanálise de Donald W. Winnicott. É bem sabido que o psicanalista inglês rejeitou a metapsicologia em bloco, sem poupar nem mesmo o princípio de causalidade, e a substituiu por uma teoria da "natureza humana" sem aparelhos, energias ou dualismo de forças. No lugar da parafernália ${ }^{31}$ míticometafísica da metapsicologia ortodoxa, Winnicott colocou uma idéia à primeira vista muito simples: de que o ser humano é tão somente uma amostra temporal da natureza humana, um intervalo entre dois estágios de não ser. Nesse contexto, a teoria do homem passa a tratar exclusivamente da temporalização do existir humano.

O principio básico dessa abordagem é o seguinte: a integração do existir humano no tempo não se explica causalmente, nem mesmo pertence completamente ao domínio do dizivel. Para se firmar numa vida que valha a pena ser vivida, o homem depende essencialmente da sorte e de favores imprescritiveis. Em particular, a relação da mãe suficientemente boa com o seu bebê não pode (nem deve) ser objeto de verbalização, nem, ainda menos, de teorização ou de ensino. As mães são capazes, diz Winnicott, de satisfazer as necessidades básicas dos lactentes "de uma maneira que nenhuma máquina pode imitar e que não pode ser ensinada". ${ }^{32}$ Tudo se passa como se a comunicação entre a mãe e o seu bebê fosse "uma canção sem palavras". ${ }^{33}$ É preciso deixar que ela aconteça "naturalmente", a partir da maneira como só as mães regredidas sabem fazer acontecer,

30 Sabe-se que Heidegger afirmou que a ciência não pensa. Cf. Heidegger, 1954, p. 133.

31 A palavra parafernália deriva do grego paraferna que significa "bens não compreendidos no dote".

32 Cf. Winnicott, 1988, p. 30; cf. p. 55.

33 Ibid., p. 69. 
"simplesmente por serem mães de um bebê". Trata-se aí de um tipo de conhecimento totalmente diferente do conhecimento empirico-teórico da ciência da natureza. Falando para as mães numa emissão da BBC, Winnicott afirmou: "Da mesma forma que o professor que descobriu quais vitaminas evitam o raquitismo tem algo a lhes ensinar, vocês também têm algo a ensinar a esse professor sobre uma outra espécie de conhecimento, aquela que vocês adquirem naturalmente."34

Apesar do rompimento com a metapsicologia e o modo de teorização ortodoxo, em particular, com a exigência de visualizar e verbalizar para compreender, apesar do seu recurso a uma "linguagem própria", próxima de certos poetas, filósofos e teólogos, Winnicott nunca deixou de se considerar um psicanalista. ${ }^{35}$ Ele formulou as suas razões da seguinte maneira: não obstante o seu "tatear" e a sua "falha progressiva" em finalizar qualquer projeto teórico, Freud pôs em movimento um processo que "nós e todas as gerações futuras podemos usar para a terapia, que é uma pesquisa da natureza humana, e para a pesquisa, que é uma terapia do homem" ${ }^{36}$

\section{Referências bibliográficas}

BLUM, Vera Lucia. O estatuto das entidades metapsicológicas à luz da teoria kantiana das idéias. UNICAMP, Departamento de Filosofia, tese de mestrado, 1994 (a ser publicada pela Editora CLE, da UNICAMP).

BOSS, Medard. Grundzüge der Medizin und der Psychologie, 2. ed. Bern: Hans Huber, 1975.

- Zollikoner Seminare. In: Neske, 1977, p. 31-45. (Trad. inglesa in Review of Existencial Psychology \& Psychiatry, 1978/79, v. 16, n. 1, 2 e 3, 1977, p. 7-20.)

— . (org.). Zollikoner Seminare. Frankfurt a/M: Klostermann, 1989.

BOUVERESSE, Jacques. Philosophie, mythologie et pseudo-science. Wittgenstein lecteur de Freud. Éditions de l'Eclat, 1991.

DECKER, Hannah S. Freud in Germany. Revolution and Reactin in Science, 1893-1907. N. York: International University Press, 1977.

DIJKSTERHUIS, E. J. The Mechanization of the World Picture. Oxford: Oxford University Press, 1961.

ELLENBERGER, H. F. The Discovery of the Unconscious. N. York: Basic Books, 1970.

HEIDEGGER, Martin (1927) Sein und Zeit. Tübingen: Niemeyer. Tr. br. Ser $\theta$ tempo. Petrópolis: Vozes, 1988. 2 v.

— . (1938). Die Zeit des Weltbildes. In: Heidegger, 1957, p. 69-104.

— Vorträge und Aufsatze. Pfullingen: Neske, 1954.

- Holzwege. Frankfurt a/M: Klostermann, 1957.

. Was heisst denken?. Tübingen: Niemeyer, 1961.

(1963). A tese de Kant sobre o ser. In: Heidegger, 1979, p. 235-54.

. Conferências e escritos filosóficos. São Paulo: Abril, 1979. (Os Pensadores)

34 Cf. Winnicott, 1988, p. 13.

35 Sobre o uso que Winnicott faz do poeta John Donne, cf. Loparic, 1996a, nota 2. Entre os seus poetas preferido estava ainda T. S. Eliot. É bem conhecido que Freud também recorria a "poetasfilósofos", entre eles Empédocles, Platão e Goethe, para buscar neles as suas metáforas e mitos. A diferença entre Winnicott e Freud quanto às preferências relativas a poetas mereceria ser explorada em detalhes.

36 Cf. Winnicott, 1989, p. 483. Por todas essas razōes, devemos concluir que o "psicanalista" Winnicott realiza, muito provavelmente sem saber, a tarefa heideggeriana de desconstrução de psicanálise de uma maneira mais radical que o "daseinsanalítico" Boss, aluno confesso e reconhecido do mestre alemảo. Em Loparic, 1996b, mostrei que a psicanálise winnicottiana pode ser proveitosamente interpretada a partir de Heidegger. 
LOPARIC, Zeljko. Resistências à psicanălise. Cadernos de Histónia e Filosofia da Ciência, n. 8, 1985, p. 29-49.

. Heidegger réu. Um ensaio sobre a periculosidade da filosofia. Campinas: Papirus, 1990.

Ética neopragmática e psicanálise. Percurso, n. 14, 1995a, p. 86-95.

Ética e finitude. São Paulo: Educ, 1995b.

. Winnicott e o pensamento pós-metafisico. In: CATAFESTA, Ivonise (org.). D. W. Winnicott na USP. São Paulo: Lumis, 1996a.

Descartes heuristico. Campinas: $1 \mathrm{HCH}, 1996 \mathrm{~b}$. (Coleção Trajetória, n. 5)

A origem da pergunta pela técnica em Heidegger. Cademos de História e Filosofia da Ciência, 1996c. (no prelo)

. A máquina no homem. Psicanálise e universidade. 1997. (no prelo)

NESKE, Günther (org.). Erinnerung an Martin Heidegger. Pfullingen: Neske, 1977.

POPPER, Karl R. Conjectures and Refutations. Londres: Routledge, 1963.

WINNICOTT, Donald W. O brincar e a realidade. Rio de Janeiro: Imago, 1975.

- Os bebês e as suas mães. Rio de Janeiro: Martins Fontes, 1988. 